\title{
Emergency peripartum hysterectomy in a tertiary teaching hospital in Northern Jordan: a 15-year review
}

\author{
Hasan Rawashdeh $^{{ }^{*}}$ (D) Rawan Obeidat ${ }^{1}$ and Lubna Masaadeh $^{2}$
}

\begin{abstract}
Emergency peripartum hysterectomy is a major operation performed when conservative measures fail to stop lifethreatening postpartum hemorrhage. It is associated with a high rate of maternal morbidity among survivors. This work aims to evaluate the incidence, indication, and complications of peripartum hysterectomy at King Abdulla University Hospital over 15 years. A retrospective cohort study of emergency peripartum hysterectomy. The incidence was calculated. Risk factors for abnormally adherent placenta were explored. A comparison between total and subtotal hysterectomy in terms of morbidity outcomes was conducted. The chi-square test, Fisher's exact, and independent sample $T$ test were used for analysis. Statistical significance was declared at $a<0.05$. The incidence of peripartum hysterectomy was 1.38 per 1000 births. Fifty-nine were performed after cesarean section and three were performed after vaginal delivery $(P<0.001)$. Abnormally adherent placenta (accreta, increta, and percreta) was the main indication (44.06\%). The strongest risk factor for abnormally adherent placenta was placenta previa with previous cesarean section ( $P=0.001, \mathrm{OR} 16.25,95 \% \mathrm{Cl} 1.95-135.01)$. One maternal and three neonatal deaths were recorded. Urinary bladder injury was the most frequent complication (27.11\%). No difference in morbidity was noted between total and subtotal hysterectomy. The incidence of emergency peripartum hysterectomy is increasing steadily over the last two decades in the north of Jordan. Abnormally adherent placenta is the most common indication for emergency peripartum hysterectomy. There is no significant difference between total and subtotal hysterectomy in terms of complications' development, admission to the intensive care unit, and estimated blood loss. The morbidity associated with emergency peripartum hysterectomy is significant.
\end{abstract}

Keywords: Peripartum, Hysterectomy, Jordan, Review

\section{Introduction}

Emergency peripartum hysterectomy (EPH) is a major operation performed almost always when conservative measures fail to stop life-threatening postpartum hemorrhage. Apart from the dramatic loss of future fertility, EPH has the potential to be associated with a high rate of maternal morbidity among survivors [1-4].

The worldwide incidence of emergency peripartum hysterectomy is around 1 per 1000 deliveries, being

\footnotetext{
* Correspondence: hmrawashdeh@just.edu.jo

${ }^{1}$ Department of Obstetrics and Gynaecology, Jordan University of Science and Technology (JUST), Ar Ramtha 3030, Ar-Ramtha, Irbid, Jordan Full list of author information is available at the end of the article
}

higher among low-income countries [1, 5]. Nationally, the exclusive couple of studies conducted on EPH were derived from the north of Jordan. They have shown a demonstrable rise in the incidence of emergency peripartum hysterectomy from 0.5 to 0.87 per 1000 deliveries between 1998 and 2002, respectively [6, 7]. The incidence in other parts of Jordan is largely unknown.

The indications for peripartum hysterectomy have altered significantly over the last four decades where abnormally adherent placenta has escalated rapidly over sterilization, fibroid tumors, and uterine atony, which were the most frequent indications, to become

\section{Springer Open}

(- The Author(s). 2021 Open Access This article is licensed under a Creative Commons Attribution 4.0 International License, which permits use, sharing, adaptation, distribution and reproduction in any medium or format, as long as you give appropriate credit to the original author(s) and the source, provide a link to the Creative Commons licence, and indicate if changes were made. The images or other third party material in this article are included in the article's Creative Commons licence, unless indicated otherwise in a credit line to the material. If material is not included in the article's Creative Commons licence and your intended use is not permitted by statutory regulation or exceeds the permitted use, you will need to obtain permission directly from the copyright holder. To view a copy of this licence, visit http://creativecommons.org/licenses/by/4.0/. 
the far leading indication for all peripartum hysterectomy cases $[1,8,9]$.

The objective of this study was first to evaluate the incidence, indication, and complications of EPH at a tertiary obstetric referral hospital in the north of Jordan. Then, we assessed whether total or subtotal hysterectomy procedures had produced different outcomes. Finally, we looked for risk factors for abnormally adherent placenta among this cohort of patients.

\section{Materials and methods}

All cases of emergency peripartum hysterectomy performed at King Abdulla University Hospital (KAUH), a tertiary referral teaching university hospital in the north of Jordan, between January 2004 and December 2019 were reviewed retrospectively. The ICD-10 coding system, histopathology reports, and operating theater records were used to identify the cases. Further details were recruited from the patients' medical records after removing duplicate entries.

Although many authors define emergency peripartum hysterectomy $(\mathrm{EPH})$ as a hysterectomy procedure performed within 6 weeks postpartum, we have defined $\mathrm{EPH}$ as a hysterectomy performed after 20 weeks of gestation, within $48 \mathrm{~h}$ of delivery for catastrophic postpartum hemorrhage uncontrolled by medical and surgical therapies. Four cases of planned peripartum hysterectomy procedures were identified and excluded. A total number of sixty-two women with EPH were identified over the 15 years. Out of the sixty-two entries, three women had incomplete medical records and they were included only during measuring the incidence. Fifty-nine women had complete medical records, and their data were used for full analysis. The operations included were all performed by at least two consultants, where at least one of them was an expert gynecologist, as per the local policy of the department. All urinary bladder injuries were repaired by a gynecologic oncologist or a consultant urologist, as per the local policy. Out of the fiftynine procedures, forty were performed by a gynecologic oncologist and a consultant urologist attended nineteen times.

Maternal characteristics including demographics, past obstetric history, details of the current pregnancy and delivery, and details of the hysterectomy and complications were obtained.

The patients were divided into two groups according to the type of hysterectomy they had whether total and subtotal and the outcomes were compared between both groups.

Furthermore, the patients were divided into two other groups according to the histologic type of placentation into normal and abnormally adherent placenta to assess the risk factors for its development.
Abnormally adherent placenta was defined as placenta accrete, increta, and percreta.

The incidence of EPH was presented as the number of hysterectomies per 1000 births. Descriptive statistics were calculated and represented as frequency (\%), mean (standard deviation (SD)), or median (interquartile range (IQR)) as appropriate. Data were expressed as categorical variables. The Chisquare test or Fisher's exact test, as appropriate, were used to test for association between categorical factors. The odds ratio (OR) was also reported. Independent sample $T$ test was used for parametric continuous factors. Statistical significance was declared at $\alpha<0.05$ (two-sided).

Ethics approval was granted from the Institutional Review Board (IRB) committee at KAUH.

\section{Results}

Over the 15 years of the study, there were 44,905 total number of deliveries at KAUH. In total, 21,077 (46.9\%) were cesarean deliveries, while 23,828 (53.1\%) were vaginal deliveries. Sixty-two of them required EPH, yielding an incidence of 1.38 per 1000 deliveries. Fifty-nine EPH were performed after cesarean section giving an incidence of 2.79 per 1000 deliveries, while only $3 \mathrm{EPH}$ were performed after vaginal delivery giving an incidence of 0.12 per 1000 deliveries suggesting that cesarean delivery has an extremely significant association with EPH $(P<$ 0.001). Oxytocin, ergometrine, and bimanual compression were applied for all participants before hysterectomy, while the B-Lynch procedure was applied seven times. The internal iliac artery was ligated once and uterine artery embolization was tried four times. Salpingo-oophorectomy was performed five times unilaterally and once bilaterally.

Table 1 demonstrates that the mean maternal age was $35.83 \pm 4.47$ ranging from 21 to 47 years and the mean BMI was $30.57 \pm 4.73$. Regarding their obstetric history, all women were multiparous with a median parity of 4 and 22 of them were grand multiparous, while the median gravidity was 6 . The median number of previous cesarean section for the cohort was 3 . Most of them (54 cases, 91.52\%) had at least one cesarean section and forty-seven (79.66\%) had 2 or more cesarean sections.

With regard to the last delivery, the mean gestational age at delivery was $35+2 \pm$ (3) ranging from 25 to 39 weeks. Nearly half of deliveries (28 cases, $47.45 \%$ ) were emergency cesarean section, while only $5.08 \%$ had vaginal deliveries, as shown in Table 1.

Regarding the presence of intraoperative gynecologic findings, a broad ligament fibroid was found incidentally in one patient who had EPH for placenta accrete. 
Table 1 Characteristics of women, deliveries, and peripartum hysterectomies

\begin{tabular}{ll}
\hline Clinical features & \\
Maternal age in years, mean (SD) & 35.83 \\
& $(4.47)$ \\
BMI, mean (SD) & 30.57 \\
& $(4.73)$ \\
Gravidity, median (IQR) & $5.79(4-7)$ \\
Parity, median (IQR) & $3.96(3-5)$ \\
Previous cesarean section, median (IQR) & $2.93(2-4)$ \\
Previous cesarean section, $n$ (\%) & $54(91.52)$ \\
$\geq 2$ previous cesarean section, $n$ (\%) & $47(79.66)$ \\
Previous uterine curettage, $n$ (\%) & $21(35.59)$ \\
Delivery & \\
Gestational age in weeks, mean (SD) & $35+2(3)$ \\
Vaginal delivery, $n$ (\%) & $3(5.08)$ \\
Elective cesarean section, $n$ (\%) & $28(47.45)$ \\
Emergency cesarean section, $n$ (\%) & $28(47.45)$ \\
Peripartum hysterectomy & \\
Total hysterectomy, $n$ (\%) & $42(71.18)$ \\
Subtotal hysterectomy, $n$ (\%) & $17(28,81)$ \\
Hysterectomy performed during cesarean section, $n(\%)$ & $48(81.35)$ \\
Reopening after cesarean section to perform & 8 (13.55) \\
hysterectomy, $n$ (\%) & \\
\hline
\end{tabular}

\section{Abnormally adherent placenta}

Operation notes and histopathology reports were reviewed to determine the main indication of EPH. Abnormally adherent placenta was the main indication for $\mathrm{EPH}$ in this cohort representing (26 cases, 44.06\%), as shown in Table 2. However, placenta previa was dominant in $77.96 \%$ of all cases and it was a concomitant finding in all cases of abnormally adherent placenta except one. This indicates that placenta previa is a major risk factor for abnormally adherent placenta $(P=0.003)$, as Table 3 illustrates. The association between previous cesarean section and abnormally adherent placenta was

Table 2 Histopathological indications for peripartum hysterectomy

\begin{tabular}{ll}
\hline Indications & $\boldsymbol{n}$ (\%) \\
\hline Abnormally adherent placenta & $26(44.06)$ \\
Placenta accreta & $7(11.86)$ \\
Placenta increta & $13(22.03)$ \\
Placenta percreta & $6(10.16)$ \\
Placenta previa & $20(33.89)$ \\
Uterine atony & $7(11.86)$ \\
Uterine rupture & $4(6.77)$ \\
Extension during cesarean section & $2(3.38)$ \\
\hline
\end{tabular}

not statistically significant $(P=0.06)$, although all women with abnormally adherent placenta had a previous cesarean delivery. On the other hand, having 2 or more cesarean sections was a significant risk factor for abnormally adherent placenta $(P=0.04)$. The strongest risk factor for abnormally adherent placenta was placenta previa with previous cesarean section $(P=0.001)$. Furthermore, being 35 years old and above and a previous history of evacuation were found to be risk factors, while grand parity and preterm delivery were not.

\section{Total versus subtotal hysterectomy outcome}

Regarding the type of hysterectomy procedure performed, $42(71.18 \%)$ were total while 17 (28.82\%) were subtotal. No significant difference was noticed between both groups in terms of complications' development, admission to the intensive care unit, estimated blood loss, and the number of packed red blood cells or total blood products transfused, as demonstrated in Table 4.

\section{Complications}

There were $3(5.08 \%)$ cases of neonatal deaths and one case of maternal death $(1.69 \%)$ for a patient who had placenta previa complicated by placenta increta after 4 previous cesarean sections. This patient had developed disseminated intravascular coagulopathy (DIC) and multiple organ failure. Thirty-four women (57.62\%) experienced no complications after EPH. The remaining 25 women $(42.37 \%)$ have experienced at least one complication where inadvertent injury to the adjacent structures mainly the urinary bladder was the commonest, while febrile illness was the second most common complication affecting $27.11 \%$ of them, as shown in Table 5. The mean blood loss for all women was $3438 \mathrm{~mL} \pm 2342$. The mean number of hospital stay in days was $5.2 \pm 4.1$.

\section{Discussion}

The most recent systemic review has shown that the incidence of EPH for low-income countries was 2.8 per 1000 deliveries [5]. The incidence of our institution (1.38 per 1000) is nearly half the overall incidence for places with a similar income. Although our number is comparable to others and looks reassuring, it is actually alarming when we compare it with the earlier studies conducted in a nearby hospital (Princess Badeea Teaching Hospital) in Northern Jordan. The numbers are showing a steady increase in the incidence of EPH from 0.5 in 1998 to 0.87 in 2002 ending by 1.38 in 2020 .

There is no national database in Jordan for EPH and cesarean section yet. Therefore, it is difficult to generalize the finding in one place to the whole country. However, the available studies for the cesarean section rate in Jordan are showing similar trends of rising rates especially among apparently low-risk mothers [10, 11]. 
Table 3 Risk factors for developing abnormally adherent placenta

\begin{tabular}{|c|c|c|c|c|c|}
\hline Risk factor & $\begin{array}{l}\text { Normal placentation (\%) }(n= \\
\text { 33) }\end{array}$ & $\begin{array}{l}\text { Abnormal placentation (\%) }(n= \\
\text { 26) }\end{array}$ & $\begin{array}{l}\text { Odds } \\
\text { ratio }\end{array}$ & $95 \% \mathrm{Cl}$ & $\begin{array}{l}P \\
\text { value }\end{array}$ \\
\hline Previous cesarean section & & & 10.22 & $\begin{array}{l}(0.53- \\
194.05)\end{array}$ & 0.06 \\
\hline $\mathrm{No}^{\mathrm{a}}$ & $5(100 \%)$ & $0(0.0 \%)$ & & & \\
\hline Yes & $28(51.9 \%)$ & $26(48.1 \%)$ & & & \\
\hline$\geq 2$ previous cesarean section & & & 5.21 & $(1.03-26.42)$ & 0.04 \\
\hline $\mathrm{No}^{\mathrm{a}}$ & $10(83.3 \%)$ & $2(16.7 \%)$ & & & \\
\hline Yes & $23(48.9 \%)$ & $24(51.1 \%)$ & & & \\
\hline Placenta previa & & & 14.28 & $\begin{array}{l}(1.71- \\
119.12)\end{array}$ & 0.003 \\
\hline $\mathrm{No}^{\mathrm{a}}$ & $12(92.3 \%)$ & $1(7.7 \%)$ & & & \\
\hline Yes & $21(45.7 \%)$ & $25(54.3 \%)$ & & & \\
\hline $\begin{array}{l}\text { Previous cesarean section and placenta } \\
\text { previa }\end{array}$ & & & 16.25 & $\begin{array}{l}(1.95- \\
135.01)\end{array}$ & 0.001 \\
\hline $\mathrm{No}^{\mathrm{a}}$ & $13(92.8 \%)$ & $1(7.2 \%)$ & & & \\
\hline Yes & $20(44.4 \%)$ & $25(55.6 \%)$ & & & \\
\hline Age (years) & & & 3.50 & $(1.06-11.52)$ & 0.03 \\
\hline$<35^{\mathrm{a}}$ & $15(75 \%)$ & $5(25 \%)$ & & & \\
\hline$\geq 35$ & $18(46.2 \%)$ & $21(53.8 \%)$ & & & \\
\hline Previous evacuation & & & 3.12 & $(1.03-9.45)$ & 0.04 \\
\hline $\mathrm{No}^{\mathrm{a}}$ & $25(65.8 \%)$ & $13(34.2 \%)$ & & & \\
\hline Yes & $8(38.1 \%)$ & $13(61.9 \%)$ & & & \\
\hline Grand parity & & & 0.81 & $(0.28-2.36)$ & 0.70 \\
\hline $\mathrm{No}^{\mathrm{a}}$ & $20(51.3 \%)$ & $17(48.8 \%)$ & & & \\
\hline Yes & $13(58.3 \%)$ & $9(41.7 \%)$ & & & \\
\hline Gestational age at delivery (weeks) & & & 1.39 & $(0.48-4.02)$ & 0.54 \\
\hline$\geq 37^{\mathrm{a}}$ & $14(60.9 \%)$ & $9(39.1 \%)$ & & & \\
\hline$<37$ & 19 (52.8\%) & $17(47.2 \%)$ & & & \\
\hline
\end{tabular}

$\mathrm{Cl}$ confidence interval

${ }^{\mathrm{a}}$ Reference group

Table 4 Outcomes of total hysterectomy versus subtotal hysterectomy

\begin{tabular}{|c|c|c|c|}
\hline Outcomes & Total hysterectomy $(n=42)$ & Subtotal hysterectomy $(n=17)$ & $P$ value \\
\hline Encountered complications & & & 0.8 \\
\hline No & $24(57.1 \%)$ & $10(58.8 \%)$ & \\
\hline Yes & $18(42.9 \%)$ & $7(41.2 \%)$ & \\
\hline Urinary tract injury & & & 0.94 \\
\hline No & $30(71.4 \%)$ & $12(70.6 \%)$ & \\
\hline Yes & $12(28.6 \%)$ & $5(29.4 \%)$ & \\
\hline ICU admission & & & 0.48 \\
\hline No & $23(54.8 \%)$ & $11(64.7 \%)$ & \\
\hline Yes & $19(45.2 \%)$ & $6(35.3 \%)$ & \\
\hline Packed RBC, unit (IQR) & $6(4-9)$ & $6(2-8)$ & 0.52 \\
\hline Total blood product, unit (IQR) & $14.5(8-23.75)$ & $8(4-20)$ & 0.84 \\
\hline Estimated blood loss, mL (IQR) & $3000(2125-4000)$ & $2500(2000-3500)$ & 0.99 \\
\hline
\end{tabular}

Descriptive provided as either frequency (\%) or median (IQR) 
Table 5 Complications encountered with peripartum hysterectomy

\begin{tabular}{lc}
\hline Complications & $\boldsymbol{n}$ (\%) \\
\hline Febrile illness & $16(27.11)$ \\
Infection (positive culture) & $13(22.03)$ \\
Septicemia & $2(3.38)$ \\
Urinary tract infection & $8(13.55)$ \\
Wound & $2(3.38)$ \\
Chest & $1(1.69)$ \\
Injury to adjacent structures & $18(30.50)$ \\
Urinary bladder & $16(27.11)$ \\
Ureter & $1(1.69)$ \\
Bowel & $1(1.69)$ \\
Acute renal failure & $2(3.38)$ \\
Disseminated intravascular coagulopathy & $10(16.94)$ \\
Transfusion-related acute lung injury & $1(1.69)$ \\
Maternal death & $1(1.69)$ \\
Neonatal death & $3(5.08)$ \\
\hline
\end{tabular}

For example, one study has shown that the rate has jumped from $18.2 \%$ in 2002 to $30.3 \%$ in 2012 [10]. This steady increase in the cesarean section rate can explain, by itself, the gradual rise of EPH incidence since a direct association between cesarean section and EPH was described by the United Kingdom Obstetrics Surveillance System (UKOSS) [12]. Moreover, another explanation can be made as the rise in the cesarean section rate in the past two decades has created a new population of scarred uteruses where the risk of EPH will be significantly higher when placenta previa complicates it, as Shamsa et al. suggested [4].

Our finding of an extremely significant association between placenta previa and previous cesarean section with abnormally adherent placenta $(P=0.001)$ in our population was similar to other studies in different populations suggesting that the finding is genuine and universal [4]. Therefore, women with this risk factor should be referred to a tertiary center where ICU facilities and blood bank services are available.

Similar to other studies that looked for differences in the outcomes between total and subtotal hysterectomy, we found no statistically significant difference in maternal morbidity [3]. Hence, we recommend to leave the decision to the operating surgeon according to the surgical situation during the procedure.

Our limitation in the study is that our institution (KAUH) is a referral center receiving high-risk cases. Therefore, the numbers of EPH and cesarean section might not represent the actual number when general obstetric practice is not the usual daily activity.
Based on the above evidence, we are concerned that the rate of EPH will continue to rise in the future threatening mothers' lives and well-being if no real actions are taken to prevent unnecessary first cesarean sections. Thus, we strongly advise decision-makers to create a national registry for cesarean section and EPH which will guide clinicians to monitor the trends and start applying appropriate policies.

\section{Conclusions}

The incidence of emergency peripartum hysterectomy is increasing steadily over the last two decades in the north of Jordan. Abnormally adherent placenta is the commonest indication for emergency peripartum hysterectomy. There is a strong association between placenta previa and previous cesarean section with abnormally adherent placenta.

We recommend to work on lowering the rate of cesarean section, in order to stop the steady rise of peripartum hysterectomy. This will lower the incidence of abnormally adherent placenta which is the main cause of peripartum hysterectomy. Also, a clear guideline has to be distributed to all peripheral hospitals to refer all patients with placenta previa on top of previous cesarean scars to tertiary hospitals since the risk of abnormally adherent placenta and the need for peripartum hysterectomy is high.

There is no significant difference between total and subtotal hysterectomy in terms of complications' development, admission to the ICU, and estimated blood loss. Therefore, we do not recommend one approach in favor of the second approach. The surgeon's decision and expertise should be the main guide in these situations.

The morbidity associated with emergency peripartum hysterectomy, apart from loss of fertility is significant. Thus, a careful psychological assessment and emotional support is crucial in these cases.

\section{Abbreviations \\ EPH: Emergency peripartum hysterectomy; DIC: Disseminated intravascular coagulopathy; RBCs: Red blood cells; ICU: Intensive care unit; SD: Standard deviation; IQR: Interquartile range; UKOSS: United Kingdom Obstetrics Surveillance System}

\section{Acknowledgements}

Not applicable.

\section{Authors' contributions}

H.R.: Suggestion of the idea, data collection, data analysis, reviewing the literature, and writing and editing the manuscript. R.O.: Data collection, data analysis, reviewing the literature, and editing the manuscript. L.M.: Data collection, data analysis, reviewing the literature, and editing the manuscript. The author(s) read and approved the final manuscript.

\section{Authors' information}

H.R.: Assistant Professor at the Department of Obstetrics and Gynaecology, Jordan University of Science and Technology (JUST), Irbid, Jordan. R.O.: Assistant Professor at the Department of Obstetrics and Gynaecology, Jordan University of Science and Technology (JUST), Irbid, Jordan.

L.M.: Senior resident at the Department of Obstetrics and Gynaecology, King Abdulla University Hospital (KAUH), Ar-Ramtha, Jordan. 


\section{Funding}

This research did not receive any specific funding.

\section{Availability of data and materials}

The data that support the findings of this study are available from King Abdulla University Hospital (KAUH) [third party]. Restrictions apply to the availability of these data, which were used under license for this study. Data are available [from the corresponding author] with the permission of the IRB committee at KAUH [third party].

\section{Ethics approval and consent to participate}

Ethical approval for this retrospective study was granted by the IRB committee at King Abdulla University Hospital. Reference number: (89/132/ 2020), on 13 April 2020.

\section{Consent for publication}

Not applicable.

\section{Competing interests}

The authors declare that they have no competing interests.

\section{Author details}

${ }^{1}$ Department of Obstetrics and Gynaecology, Jordan University of Science and Technology (JUST), Ar Ramtha 3030, Ar-Ramtha, Irbid, Jordan.

${ }^{2}$ Department of Obstetrics and Gynaecology, King Abdulla University Hospital (KAUH), Ar Ramtha, Ar-Ramtha 3030, Jordan.

Received: 9 October 2020 Accepted: 8 February 2021

Published online: 18 February 2021

\section{References}

1. de la Cruz CZ, Thompson EL, O'Rourke K, Nembhard WN (2015) Cesarean section and the risk of emergency peripartum hysterectomy in high-income countries: a systematic review. Arch Gynecol Obstet 292(6):1201-1215. https://doi.org/10.1007/s00404-015-3790-2

2. Akintayo AA, Olagbuji BN, Aderoba AK, Akadiri O, Olofinbiyi BA, Bakare B (2016) Emergency peripartum hysterectomy: a multicenter study of incidence, indications and outcomes in southwestern Nigeria. Matern Child Health J 20(6):1230-1236. https://doi.org/10.1007/s10995-016-1924-1

3. D'Arpe S, Franceschetti S, Corosu R, Palaia I, Di Donato V, Perniola G, Muzii L, Benedetti Panici P (2015) Emergency peripartum hysterectomy in a tertiary teaching hospital: a 14-year review. Arch Gynecol Obstet 291(4):841847. https://doi.org/10.1007/s00404-014-3487-y

4. Shamsa A, Harris A, Anpalagan A (2015) Peripartum hysterectomy in a tertiary hospital in Western Sydney. J Obstet Gynaecol 35(4):350-353. https://doi.org/10.3109/01443615.2014.961907

5. van den Akker T, Brobbel C, Dekkers OM, Bloemenkamp KW (2016) Prevalence, indications, risk indicators, and outcomes of emergency peripartum hysterectomy worldwide. Obstet Gynecol 128(6):1281-1294

6. Abu-Heija AT, Jallad FF (1999) Emergency peripartum hysterectomy at the Princess Badeea Teaching Hospital in north Jordan. J Obstet Gynaecol Res 25(3):193-195. https://doi.org/10.1111/j.1447-0756.1999.tb01146.x

7. El-Jallad MF, Zayed F, Al-Rimawi HS (2004) Emergency peripartum hysterectomy in Northern Jordan: indications and obstetric outcome (an 8-year review). Arch Gynecol Obstet 270(4):271-273. https://doi.org/10.1007/s00404-003-0563-0

8. Castaneda S, Karrison T, Cibils LA (2000) Peripartum hysterectomy. J Perinat Med 28(6):472-481. https://doi.org/10.1515/JPM.2000.064

9. Bateman BT, Mhyre JM, Callaghan WM, Kuklina EV (2012) Peripartum hysterectomy in the United States: nationwide 14 year experience. Am J Obstet Gynecol 206(1):63.e61-63.e638. https://doi.org/10.1016/j.ajog.2011.07.030

10. Rifai RA (2014) Rising cesarean deliveries among apparently low-risk mothers at university teaching hospitals in Jordan: analysis of population survey data, 20022012. Glob Health 2(2):195-209. https:/doi.org/10.9745/ghsp-d-14-00027

11. Hindawi IM, Meri ZB (2004) The Jordanian cesarean section rate. Saudi Med J 25(11):1631-1635

12. Knight M, UKOSS (2007) Peripartum hysterectomy in the UK: management and outcomes of the associated haemorrhage. BJOG 114(11):1380-1387

\section{Publisher's Note}

Springer Nature remains neutral with regard to jurisdictional claims in published maps and institutional affiliations.

\section{Submit your manuscript to a SpringerOpen ${ }^{\circ}$ journal and benefit from:}

- Convenient online submission

- Rigorous peer review

- Open access: articles freely available online

- High visibility within the field

- Retaining the copyright to your article

Submit your next manuscript at $\boldsymbol{\nabla}$ springeropen.com 